\title{
Improved fiber probe for laser tissue ablation with integrated distributed temperature sensor
}

Yu Liu, Riccardo Gassino, Hao Yu, Andrea Braglia, Alberto Vallan, Guido Perrone, Daniele Tosi

- School of Engineering

\begin{abstract}
The paper presents a new all-fiber probe for laser induced thermal ablation of solid tumor cells that integrates a beam delivery fiber with nanostructured surface to shape the laser irradiation pattern and a chirped grating to allow real-time monitoring of the temperature profile. A theoretical model of the sensor to study the temperature profile recovery algorithm and experimental validations using phantoms are discussed.
\end{abstract}

Original language

Title of host publication

Publisher

Volume

ISBN (Electronic)

State

Event
English

Optical Fibers and Sensors for Medical Diagnostics and Treatment Applications XVI

$\underline{\text { SPIE }}$

9702

9781628419368

Published - 2016

Optical Fibers and Sensors for Medical Diagnostics and Treatment Applications XVI - San Francisco, United States

Liu, Y., Gassino, R., Yu, H., Braglia, A., Vallan, A., Perrone, G., \& Tosi, D. (2016). Improved fiber probe for laser tissue ablation with integrated distributed temperature sensor. In Optical Fibers and Sensors for Medical Diagnostics and Treatment Applications XVI. (Vol. 9702). [97020G] SPIE. DOI: 10.1117/12.2211292 